CLINICAL STUDY

\title{
Characterization of the RET protooncogene transmembrane domain mutation S649L associated with nonaggressive medullary thyroid carcinoma
}

\author{
Mario Colombo-Benkmann, Zhenpeng Li $^{1}$, Burkhard Riemann ${ }^{2}$, Karin Hengst ${ }^{3}$, Hermann Herbst ${ }^{4}$, Roger Keuser ${ }^{5}$, \\ Ute Groß $^{6}$, Susanne Rondot ${ }^{7}$, Friedhelm Raue ${ }^{7}$, Norbert Senninger, Brigitte M Pützer ${ }^{1}$ and Karin Frank-Raue ${ }^{7}$ \\ Department of General Surgery, Westfälische Wilhelms-Universität Münster, 48149 Münster, Germany, ${ }^{1}$ Department of Vectorology and Experimental \\ Gene Therapy, Rostock University, 18057 Rostock, Germany, ${ }^{2}$ Department of Nuclear Medicine, ${ }^{3}$ Department of Internal Medicine, ${ }^{4}$ Gerhard-Domagk- \\ Institute of Pathology, Westfälische Wilhelms-Universität Münster, 48149 Münster, Germany, ${ }^{5}$ Praxis für Innere Medizin, Koblenz, Germany, \\ ${ }^{6}$ Endokrinologikum Hamburg, 22767 Hamburg, Germany and ${ }^{7}$ Endokrinologisch-Humangenetische Gemeinschaftspraxis, Brückenstrasse 21,69120 \\ Heidelberg, Germany \\ (Correspondence should be addressed to K Frank-Raue; Email: karin.frankraue@raue-endokrinologie.de)
}

\begin{abstract}
Context: For rare and novel RET mutations associated with hereditary medullary thyroid carcinoma (MTC), clinical and functional studies are needed to classify the RET mutation into one of the three clinical risk groups. Objective: We analyzed proliferative properties and clinical implications associated with the RET protooncogene transmembrane domain mutation S649L.

Design: The transforming potential and mitogenic properties of S649L mutation were investigated clinically and by evaluating kinase activity, cell proliferation, and colony formation.

Patients: Fifteen individuals from five kindreds were identified as carriers of a RET protooncogene mutation in exon 11 codon 649 (TCG ${ }^{\text {Ser }} \rightarrow \mathrm{TTG}^{\mathrm{Leu}}$ ). In two out of five index patients, a second RET mutation (C634W or V804L) was detected.

Results: Eight gene carriers were operated on. Histology revealed MTC and C-cell hyperplasia in three index and three screening patients respectively. In all other gene carriers (aged 41-64 years), calcitonin levels were in the normal range, and pentagastrin-stimulated calcitonin levels were $<100 \mathrm{pg} / \mathrm{ml}$. Therefore, thyroidectomy had not yet been performed. In one index patient carrying the S649L mutation, hyperparathyroidism was confirmed histologically. RET S649L-expressing NIH3T3 cells exhibited a clear increase of phosphotyrosine and proliferation rate when compared with parental NIH3T3 cells but a significantly lower kinase activity and cell growth rate when compared with RET C634R-expressing cells. When compared with RET C634R, the S649L mutant showed moderate transforming potential with small-sized colonies.

Conclusions: Our clinical and in vitro findings indicate that the transmembrane RET S649L mutation is associated with late-onset non-aggressive disease. Recommendations for prophylactic thyroidectomy should be individualized depending on stimulated calcitonin levels.
\end{abstract}

European Journal of Endocrinology 158 811-816

\section{Introduction}

Missense germline mutations in the RET protooncogene are associated with multiple endocrine neoplasia type 2 (MEN2) and familial medullary thyroid carcinoma (MTC) $(1,2)$. Detection of the mutant alleles in kindred members predicts disease inheritance and provides the basis for prophylactic thyroidectomy in children $(3,4)$. There is an age-related progression from C-cell hyperplasia $(\mathrm{CCH})$ to MTC correlating with the transforming potential of the respective RET mutations (5). Codonspecific prognosis would allow individualized risk stratification (level 1-3 risk groups) for patients (6).

For newly identified or rare mutations in the RET gene, the causative role of the mutation and the genotype-phenotype relationship must be evaluated to define the mutation's codon-specific risk level. Here, we describe 15 individuals from five kindreds who were identified as carriers of a RET mutation in exon 11 codon 649 (TCG $\rightarrow$ TTG). Our clinical analysis and functional studies indicate that this S649L mutation in the transmembrane domain of RET is characterized by low penetrance of MTC, a relatively low aggressive potential of the disease (level 1), and rare further endocrinopathies.

\section{Subjects and methods}

Clinical work-up and RET mutation analysis were performed on five kindreds from two centers that had been diagnosed with MTC or hyperparathyroidism. 
Informed consent was obtained from all subjects. Fifteen individuals were identified as mutant RET gene carriers (S649L). The study population consisted of five index and ten screening patients.

Calcitonin levels were measured by chemiluminescence assay (Nichols Institute, Bad Vilbel, Germany). The normal basal levels were $<10.3$ and $<4.3 \mathrm{pg} / \mathrm{ml}$ for males and females respectively. After total thyroidectomy, no increment in calcitonin after pentagastrin administration $(0.5 \mu \mathrm{g} / \mathrm{kg}$ body weight i.v.) was considered normal.

In all patients, germline RET mutation analysis was performed as described previously (7). Allele-specific PCR for the linkage analysis of exon 11 mutations was performed with normal (5'-GAAGGCAGACAGCAGCACCG-3') or mutant (5'-GAAGGCAGACAGCAGCACCA-3') codon 649-specific primers and exon 11 forward as a counterprimer. The product was sequenced as previously described (7).

\section{Histology}

$\mathrm{CCH}$ was defined as $50 \mathrm{C}$-cells per low-power field. Tumor staging was performed according to the International Union Against Cancer tumor-node-metastasis (TNM) classification from 1997.

\section{In vitro studies}

The RET51 mutant S649L was generated from the pJ7@RET51wt plasmid (a kind gift from M Bilaud) by site-directed mutagenesis using the QuikChange II XL kit (Stratagene, La Jolla, CA, USA). NIH3T3 stable cell lines expressing RET S649L and C634R were obtained and analyzed for equal RET protein expression as described previously (8). The cell growth rate and transforming potential were determined as described (8). For the XTT assay, cells seeded in 96-well plates were incubated with TACS XTT labeling mixture (Trevigen Inc., Gaithersburg, MD, USA) for $4 \mathrm{~h}$. Conversion of XTT to formazan was quantified by measuring the absorbance at $450 \mathrm{~nm}$.

\section{In vitro kinase activity assay}

Subconfluent NIH3T3 cells, and stable cell lines expressing RET C634R or RET S649L were lysed in lysis buffer (150 mM NaCl, $0.5 \mathrm{mM}$ EDTA, $1 \mathrm{mM}$ dithiothreitol (DTT), 1\% NP-40, $0.5 \%$ sodium deoxycholate, $0.1 \%$ SDS, $100 \mathrm{mM}$ sodium vanadate, $50 \mathrm{mM}$ Tris; $\mathrm{pH}$ 8.0) supplemented with protease inhibitors. Whole RET protein was immunoprecipitated from cell extracts containing $500 \mathrm{mg}$ total protein with RET 51 (Santa Cruz, Biotechnology, Heidelberg, Germany) polyclonal antibody. Immunoprecipitation was carried out overnight at $4{ }^{\circ} \mathrm{C}$, and immunocomplexes were harvested by addition of $\mathrm{A} / \mathrm{G}$ agarose beads. After extensive washing, immunocomplexes were eluted in tyrosine kinase (TK) buffer (60 mM HEPES ( $\mathrm{pH} 7.5$ ), $5 \mathrm{mM} \mathrm{MgCl}_{2}, 5 \mathrm{mM}$ $\mathrm{MnCl}_{2}, 3 \mathrm{mM} \mathrm{Na}_{3} \mathrm{VO}_{4}, 1.25 \mathrm{mM}$ DTT, and $200 \mathrm{mM}$ ATP) and TK activity was measured using a TK activity assay kit (Chemicon, Temecula, CA, USA) according to the manufacturer's protocol.

\section{Results}

Fifteen individuals from five kindreds (male:female ratio 6:9; median age 44 years, range 20-75 years) were

Table 1 Data for 15 carriers (from five different families) of the RET S649L mutation.

\begin{tabular}{|c|c|c|c|c|c|c|c|c|}
\hline Family & Age & Sex & RET mutations & Index & $\begin{array}{l}\text { Calcitonin levels } \\
\text { preoperatively basal/ } \\
\text { stimulated }\end{array}$ & Histology & pTNM & Cured \\
\hline \multicolumn{9}{|l|}{1} \\
\hline II,5 & 29 & $\mathrm{M}$ & $649+634$ & \multirow[t]{5}{*}{ Index } & $500 /-$ & MTC, Pheo & \multirow[t]{5}{*}{ pT2NOMO } & Yes \\
\hline $\mathrm{I}, 1$ & 64 & $\mathrm{~F}$ & 649 & & $0.7 / 1$ & CCH, PTC & & Yes \\
\hline I,2 & 60 & $\mathrm{~F}$ & 649 & & $2 / 4$ & - & & - \\
\hline $\mathrm{II}, 1$ & 44 & $M$ & 649 & & $3 / 19$ & $\mathrm{CCH}$ & & Yes \\
\hline III,1 & 20 & $\mathrm{~F}$ & 649 & & $0.7 / 0.7$ & $\mathrm{CCH}$ & & Yes \\
\hline \multicolumn{9}{|l|}{2} \\
\hline $\mathrm{I}, 1$ & 69 & $\mathrm{~F}$ & 649 & \multirow[t]{5}{*}{ Index } & $-1-$ & MTC & \multirow[t]{5}{*}{ pT2NOMO } & \multirow[t]{5}{*}{ Yes } \\
\hline $\mathrm{II}, 1$ & 47 & $\mathrm{M}$ & 649 & & $1.5 / 15$ & - & & \\
\hline II,3 & 44 & M & 649 & & $17 / 81$ & $\begin{array}{l}\text { No MTC } \\
\text { No } \mathrm{CCH}\end{array}$ & & \\
\hline $\mathrm{II}, 4$ & 43 & $\mathrm{~F}$ & 649 & & $-1-$ & - & & \\
\hline II,5 & 40 & M & 649 & & $-1-$ & - & & \\
\hline \multicolumn{9}{|l|}{3} \\
\hline $\mathrm{I}, 1$ & 47 & $\mathrm{~F}$ & $649+804$ & Index & $-1-$ & MTC & \multirow[t]{5}{*}{ pT2NOMO } & \multirow[t]{5}{*}{ No } \\
\hline 4 & & & & & & & & \\
\hline II,1 & 43 & $\mathrm{~F}$ & 649 & Index & $11 / 65$ & - & & \\
\hline $\mathrm{I}, 1$ & 75 & $\mathrm{~F}$ & 649 & & $3 / 7$ & - & & \\
\hline $\mathrm{II}, 2$ & 41 & $\mathrm{~F}$ & 649 & & $3 / 8$ & - & & \\
\hline \multicolumn{9}{|l|}{5} \\
\hline II,1 & 24 & M & 649 & Index & Normal/- & HPT & & Yes \\
\hline
\end{tabular}


identified as carriers of a RET protooncogene mutation in exon 11 codon 649 (TCG $^{\text {Ser }} \rightarrow$ TTG $^{\text {Leu; }}$; Table 1 ). In two out of the five index patients, a second mutation (C634W or V804L) was detected.

\section{Clinical and histological findings}

Out of the 15 gene carriers, 8 have been operated on (Table 1). Histology revealed MTC in three index patients, including a patient carrying the RET S649L mutation and two others carrying both the S649L mutations and a second mutation (C634W or V804L). Two index patients were cured: a 69-year-old woman carrying the S649L mutation (histology showed pT2NOM0) and a 29-year-old man carrying S649L and C634W mutations (histology showed pT2NOMO). The third index patient operated on, a woman having both S649L and V804L mutations located on the same allele and tumor stage pT2NOMO at primary operation, was not cured. In this patient, pentagastrin stimulated a calcitonin increase to $39 \mathrm{pg} / \mathrm{ml}$ postoperatively and no tumor tissue could be localized.

In three screening patients of family 1 , total thyroidectomy was performed and $\mathrm{CCH}$ was detected. In one of these patients, multifocal papillary thyroid cancer was detected. In one screening patient of family 2 , histology was completely normal. In all other gene carriers, calcitonin was in the normal range, and stimulated values were $<100 \mathrm{pg} / \mathrm{ml}$ despite age range of 41-64 years. Therefore, thyroidectomy has not yet been performed.

\section{Modes of diagnosis of the five index cases}

The index patient of family 1 ( 1 II,5) was diagnosed with multiple endocrine neoplasia type 2 (MEN2A) before surgery (Fig. 1). Diagnostic work-up of chronic diarrhea unveiled pathological carcinoembryonic antigen (CEA) and basal calcitonin levels with nodular goiter. Subsequently, the patient was diagnosed as being a heterozygous carrier of a RET C634W mutation in coincidence with a S649L mutation. Mutant allelespecific PCR followed by sequencing confirmed that the mutations at C634W and S649L are located on different alleles. Furthermore, the patient had elevated urinary catecholamines and underwent right adrenalectomy for pheochromocytoma. Calcium and parathyroid hormone levels were within normal limits. Molecular genetic screening of the parents of this patient for C634W revealed no such mutation. Sequencing unveiled a heterozygous S649L mutation in the patient's mother but no further mutation. Therefore, the C634W mutation is de novo in this patient.

For the index patients of families 2 and 3, operation of nodular goiter revealed MTC (Fig. 1). In family 4, calcitonin determination in a patient with a small thyroid nodule showed slight elevation, but pentagastrin-stimulated calcitonin was $<100 \mathrm{pg} / \mathrm{ml}$. In family 5 , the index

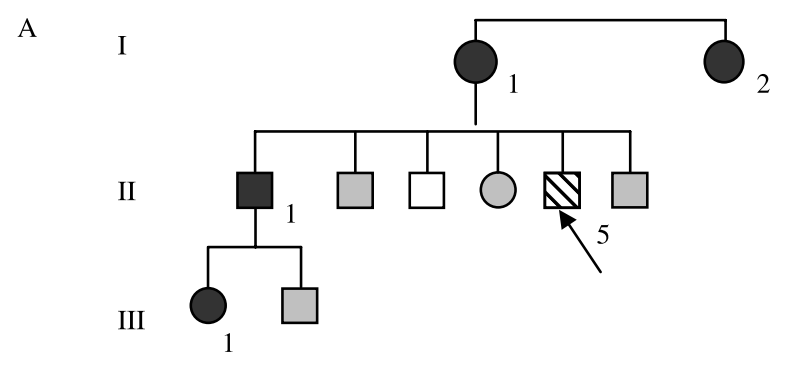

B

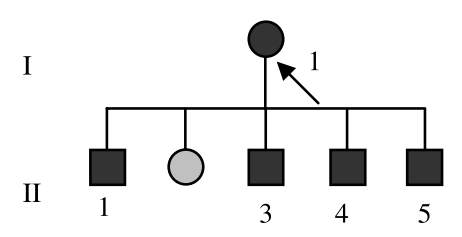

C

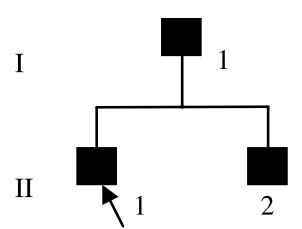

Figure 1 Pedigrees of families (A) 1, (B) 2, and (C) 4 . Black symbols depict carriers of $R E T$ protooncogene mutation S649L, grey symbols signify individuals with negative molecular genetic test results, while white symbols are those who await to be tested or were not available for it. Hatched symbols signify patients with S649L and an additional RET protooncogene mutation. Arrows depict index patients.

case was diagnosed at 24 years of age in the work-up of an operation for primary hyperparathyroidism.

\section{Functional characterization of the S649L mutation}

To determine whether the RET S649L mutation is capable of converting RET into a dominantly transforming oncogene, NIH3T3 cells were transfected with mutant cDNA to generate stable cell lines. Comparable expression of RET51 mutant proteins (C634R and S649L) in NIH3T3 stable cell lines is shown in Fig. 2A. The cell growth rate was evaluated by direct counting of cell numbers at the indicated time points, after exclusion of dead cells by trypan blue staining. As shown in Fig. 2B, cells expressing RET51 C634R (a predominant mutation in MEN2A) grew rapidly, reaching $1.03 \times 10^{6}$ cells after 4 days. $R E T$ S649L-expressing NIH3T3 cells showed a decreased proliferation rate $\left(8 \times 10^{5}\right.$ cells after 4 days $)$ compared with cells expressing RET C634R.

To confirm these data, the viabilities of NIH3T3 cell lines expressing the various RET51 mutants were determined by XTT assay. Relative cell viability was calculated after standardization with parental NIH3T3 cells. As shown in Fig. 2C, all RET51 mutants exhibited comparable cell growth during the initial 3-day 
A
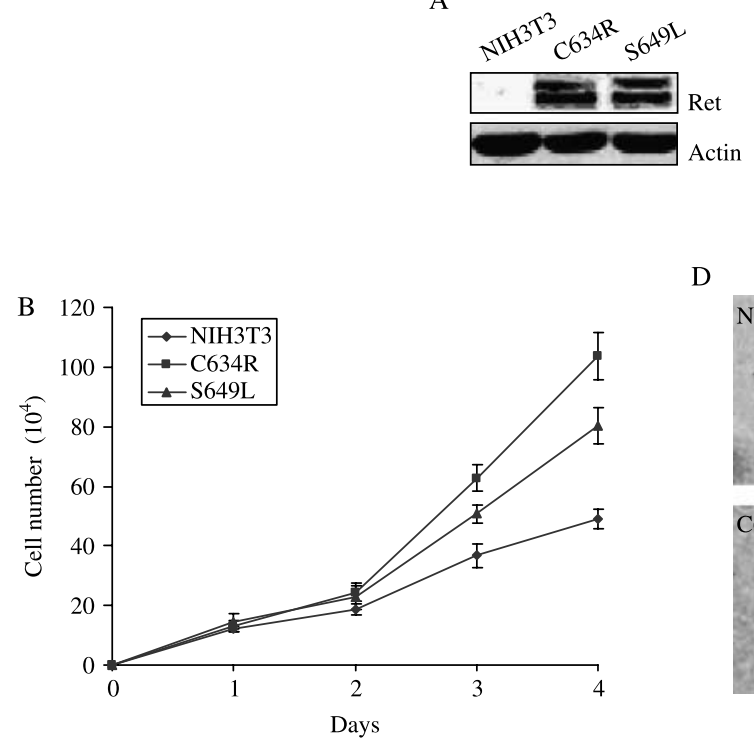

$\mathrm{D}$
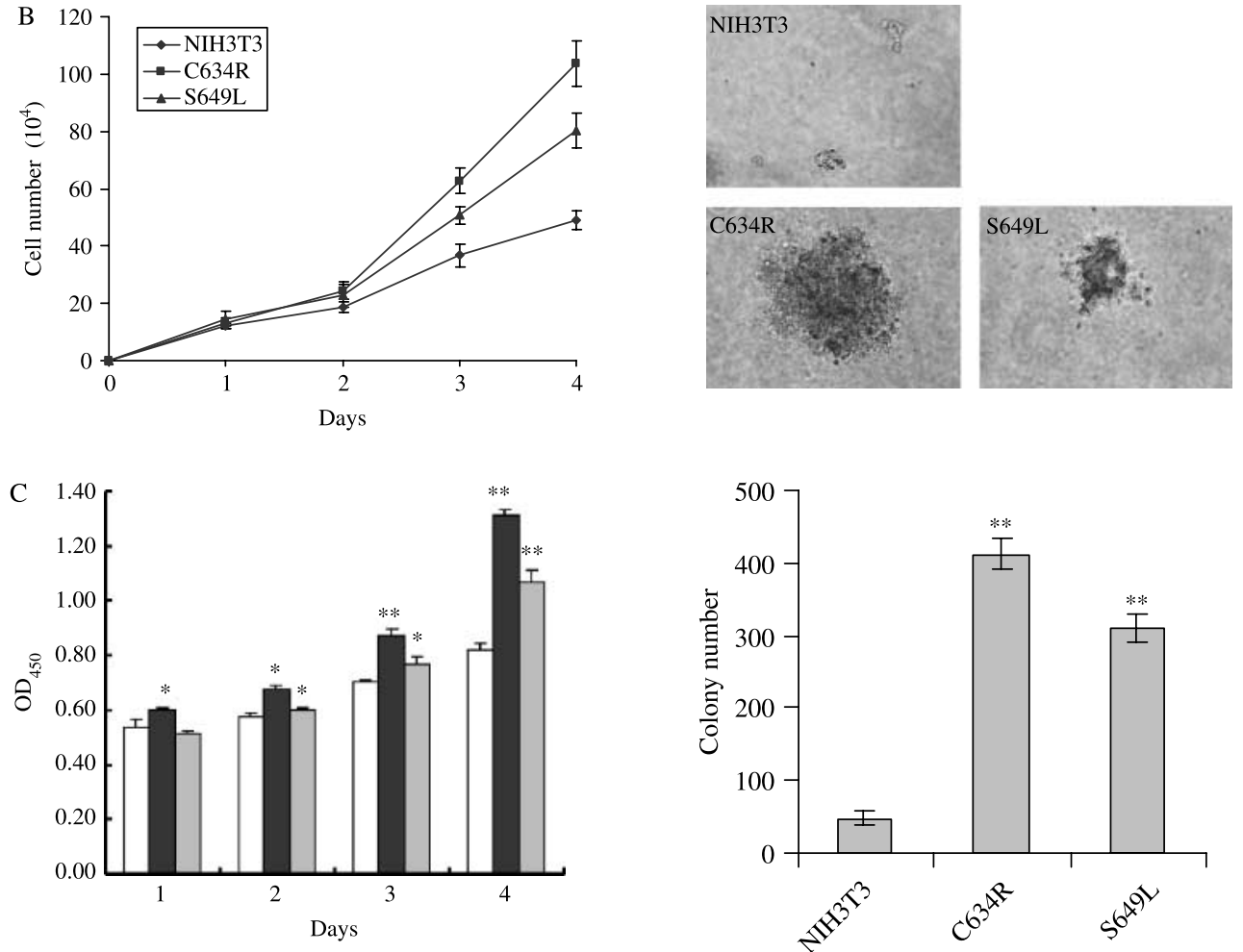

Figure 2 RET kinase activity and the influence on cell proliferation. (A) Expression of RET51 mutant proteins (C634R and S649L) in NIH3T3 cells. (B) Growth rates of cells expressing RET mutant proteins. (C) Cell viability (white bars, NIH3T3; black bars, RET51 C634R; grey bars, $R E T$ S649L; * $P<0.05,{ }^{* *} P<0.01$ ). (D) Colony formation of cells expressing $R E T$ mutant proteins; upper panel, single colony size; bottom panel, number of colonies.

observation time. At day 4, there were more viable cells expressing RET51 C634R than cells expressing RET S649L, which is most likely due to the lower proliferation rates of cells expressing the S649L mutant.

Moreover, the transforming capacities of the mutant RET proteins were assessed by their abilities to promote anchorage-independent growth of NIH3T3 cells (Fig. 2D). A strong transforming activity was observed for the RET C634R mutation, resulting in a high number of large colonies. The S649L mutant showed a moderate transforming potential with small-sized colonies.

The TK activity of RET S649L and C634R was validated by an in vitro kinase assay (Fig. 3). In both NIH3T3 clones, RET was constitutively active and exhibited a clear increase of phosphotyrosine when compared with parental NIH3T3 cells. Comparison of both the mutants revealed a significantly higher kinase activity for C634R $(P=0.041)$.

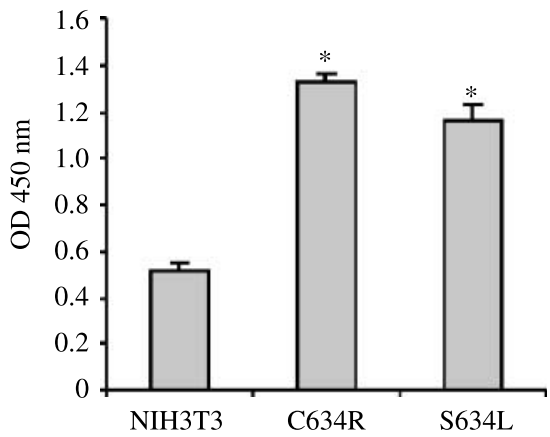

Figure 3 In vitro tyrosine kinase assay. Protein extracts from NIH3T3 transfectants stably expressing mutated forms of $R E T$ were immunoprecipitated with anti-RET and subjected to a kinase activity assay. The kinase activity was determined by differences in absorbance at OD $450 \mathrm{~nm}$. Data represent three independent experiments, bar \pm s.D. Student's $t$-test was performed to compare the kinase activity of RET mutants with parental NIH3T3 cells. ${ }^{*} P<0.01$. 


\section{Discussion}

We describe the clinical data of five families carrying a rare and not yet well-defined mutation in the transmembrane domain of the RET protooncogene in exon 11 codon 649 $\left(\mathrm{TCG}^{\mathrm{Ser}} \rightarrow \mathrm{TTG}^{\mathrm{Leu}}\right)$ and the in vitro characterization of this mutation.

Other RET transmembrane domain mutations have been identified in codons 640 (9) and 643 (9, 10); however, affected individuals carried additional, highly penetrant germline missense RET mutations. Moreover, a germline substitution in codon 648 coinciding with a codon 634 mutation has not shown oncogenic activity clinically (11). Thus, the phenotypic expression of mutations in the RET transmembrane domain has remained obscure.

The present data indicate that the RET S649L mutation harbors a low but still significant risk of MTC. Four of our patients carrying S649L alone had MTC or CCH. Moreover, in one index patient hyperparathyroidism was the leading symptom.

Gene carriers harboring two RET mutations simultaneously may have a more aggressive disease than those with the 649 RET mutation alone. In our series, the two patients with the double RET mutation showed the same tumor stage of MTC as the patient with 649 RET mutation, but age at diagnosis was more advanced in the 649 RET mutation carrier. Therefore, we conclude that disease phenotype in double RET mutation is dominated by the more severe mutations, like 634 RET mutation. In our series, there is no aggravation of disease in the patients carrying double RET mutations.

Our findings are supported by other reports of RET S649L mutations $(12,13)$. In these publications, the MTC-carrying index patients were 44 and 47 years old when first diagnosed. One 22-year-old mutation carrier had normal thyroid sonography and pentagastrinstimulated calcitonin levels. Like other level 1 mutations identified in patients with hereditary MTC, the S649L mutation displayed a low transforming potential and limited constitutive TK activity, although it did stimulate the growth of NIH3T3 cells.

In patients with MTC or MEN2A, mutations of cysteine residues in the extracellular juxtamembrane region of the RET receptor TK cause the formation of covalent receptor dimers linked by intermolecular disulfide bonds between unpaired cysteines, followed by oncogenic activation of the RET kinase. Recent observations support an active role of the transmembrane domain in non-covalent receptor-receptor interactions that may contribute to keeping receptor molecules in close proximity to each other, allowing RET homodimers to be formed by MEN2A mutations or ligand binding.

Mutations in the RET transmembrane domain such as S645A, S649A, and S653A lead to impaired selfassociation (14). When introduced in the context of C634R mutation, A639G/A641R mutations were also shown to abrogate RET transmembrane domain interactions, significantly reducing dimer formation and transforming activity of this highly oncogenic mutant. However, NIH3T3 cells expressing the S649L mutant exhibit accelerated proliferation and display a moderate transforming potential, consistent with the oncogenic activity of RET S649L in patients. Therefore, the oncogenic mechanism for the RET S649L mutation might be similar to the model derived for erythropoietin and epidermal growth factor receptors, in which activation of preformed, inactive receptor dimers is achieved via rotational changes of transmembrane and intracellular domains that bring kinases into a preferred orientation for signaling $(15,16)$.

Our clinical and in vitro data support the classification of the RET transmembrane domain mutation S649L as a level 1 mutation (6). The optimal timing for surgery in patients carrying level 1 RET mutations remains controversial. In the decision-making process, the risk of early metastases and the small risk of surgical sequelae in young children must be balanced against the biological behavior of MTC in other family members. There is good evidence in favor of thyroidectomy before the age of 6 years in patients carrying level 2 mutations, especially for a mutation in RET codon 634 (4-6). However, the decision for thyroidectomy in level 1 mutation carriers depends on personal experience and must be individualized until more data are available (17). The results of this study suggest that recommendations for prophylactic thyroidectomy in patients carrying RET mutation S649L should be individualized depending on levels of stimulated calcitonin. Further studies are necessary to confirm and extend these findings.

\section{References}

1 Mulligan LM, Kwok JBJ, Healey CS, Elsdon MJ, Eng C, Gardner E, Love DR, Mole SE, Moore JK, Papi L, Ponder MA, Telenius H, Tunnacliffe A \& Ponder BAJ. Germ-line mutations of the RET proto-oncogene in multiple endocrine neoplasia type 2a (MEN 2A). Nature 1993363 458-469.

2 Donis-Keller H, Dou S, Chi D, Carlson KM, Toshiama K, Lairmore TG, Howe JR, Moley JF, Goodfellow P \& Wells SA Jr. Mutations in the RET proto-oncogene are associated with MEN 2A and FMTC. Human Molecular Genetics 19932 851-856.

3 Wells SA, Chi DD, Toshima K, Dehner LP, Coffin CM, Dowton SB, Ivanovich JL, DeBenedetti MK, Dilley WG, Moley JF, Norton JA \& Donis-Keller H. Predictive DNA testing and prophylactic thyroidectomy in patients at risk for multiple endocrine neoplasia type 2 a. Annals of Surgery $1994220237-250$.

4 Skinner MA, Moley JA, Dilley WG, Owzar K, DeBenedetti MK \& Wells SA. Prophylactic thyroidectomy in multiple endocrine neoplasia type 2. New England Journal of Medicine 2005353 1105-1113.

5 Machens A, Niccoli-Sire P, Hoegel J, Frank-Raue K, van Vroonhoven TJ, Roeher HD, Wahl R, Lamesch P, Raue F, Conte-Devolx B, Dralle H \& for the European Multiple Endocrine neoplasia (EUROMEN) Study Group, Early malignant progression of hereditary medullary thyroid cancer. New England Journal of Medicine 2003349 1517-1525.

6 Brandi ML, Gagel RF, Angeli A, Bilezikian JP, Beck-Peccoz P, Bordi C, Conte-Devolx B, Falchetti A, Gheri RG, Libroia A, Lips CJM, Lombardi G, Mannelli M, Pacini F, Ponder B, Raue F, Skogseid B, Tamburano G, Thakker R, Thompson NW, 
Tomassetti P, Tonelli F, Wells S \& Marx S. Guidelines for diagnosis and therapy of MEN Type 1 and Type 2. Journal of Clinical Endocrinology and Metabolism 200186 5658-5671.

7 Frank-Raue K, Rondot S, Höppner W, Goretzki P, Raue F \& Meng W. Coincidence of multiple endocrine neoplasia type 1 and 2: mutations in the RET proto-oncogene and MEN1 tumor suppessor gene in a family presenting with recurrent primary hyperparathyroidism. Journal of Clinical Endocrinology and Metabolism $2005904063-4067$.

8 Mise N, Drosten M, Racek T, Tannapfel A \& Pützer BM. Evaluation of potential mechanisms underlying genotype-phenotype correlations in multiple endocrine neoplasia type 2. Oncogene 2006 25 6637-6647.

9 Tessitore A, Sinisi AA, Pasquali D, Cardone M, Vitale D, Bellastella A \& Colantuoni V. A novel case of multiple endocrine neoplasia type $2 \mathrm{~A}$ associated with two de novo mutations of the RET protooncogene. Journal of Clinical Endocrinology and Metabolism $1999 \mathbf{8 4} 3522-3527$.

10 Poturnajova M, Altanerova V, Kostalova L, Breza J \& Altaner C. Novel germline mutation in the transmembrane region of RET gene close to Cys634Ser mutation associated with MEN 2A syndrome. Journal of Molecular Medicine 200583 287-295.

11 Nunes AB, Ezabella MC, Pereira AC, Krieger JE \& Toledo SP. A novel Val648Ile substitution in RET protooncogene observed in a Cys634Arg multiple endocrine neoplasia type 2A kindred presenting with an adrenocorticotropin-producing pheochromocytoma. Journal of Clinical Endocrinology and Metabolism 2002 $875658-5661$.

12 Wiench M, Wygoda Z, Gubala E, Wloch J, Lisowska K, Krassowski J, Scieglinska D, Fiszer-Kierzkowska A, Lange D,
Kula D, Zeman M, Roskosz J, Kukulska A, Krawczyk Z \& Jarzab B. Estimation of risk of inherited medullary thyroid carcinoma in apparent sporadic patients. Journal of Clinical Oncology 200119 1374-1380.

13 Vierhapper H, Bieglmayer C, Heinze G \& Baumgartner-Parzer S. Frequency of RET proto-oncogene mutations in patients with normal and with moderately elevated pentagastrin-stimulated serum concentrations of calcitonin. Thyroid 200414 580-583.

14 Kjær S, Kurokawa K, Perrinjaquet M, Abrescia C \& Ibáňez CF. Selfassociation of the transmembrane domain of RET underlies oncogenic activation by MEN2A mutations. Oncogene 200625 7086-7095.

15 Seubert N, Royer Y, Staerk J, Kubatzky KF, Moucadel V, Krishnakumar S, Smith SO \& Constantinescu SN. Active and inactive orientations of the transmembrane and cytosolic domains of the erythropoietin receptor dimer. Molecular Cell 200312 1239-1250.

16 Moriki T, Maruyama H \& Maruyama IN. Activation of preformed EGF receptor dimers by ligand-induced rotation of the transmembrane domain. Journal of Molecular Biology 2001311 1011-1026.

17 Frank-Raue K, Buhr H, Dralle H, Klar E, Senninger N, Weber S, Rondot S, Höppner W \& Raue F. Long-term outcome in 46 gene carriers of hereditary medullary thyroid carcinoma after prophylactic thyroidectomy: impact of individual RET genotype. European Journal of Endocrinology 2006155 229-236.

Received 20 January 2008

Accepted 16 February 2008 